\title{
Lobos e bestas, vacas e eucaliptos ${ }^{1}$
}

\section{Wolves and beasts, cows and eucalyptus}

Pedro Alonso

Estudios Medioambientales y Territoriales, España

DOI: http://dx.doi.org/10.15304/ricd.3.13.7257

\section{NOTAS BIOGRÁFICAS}

Pedro Alonso é biólogo, desenvolve o seu traballo como consul tor ambiental en EMAT. Entre 2016 e 2019 participou a través desta empresa nas comisións de valoración de danos por ataque de lobo á gandería da Consellería de Medio Ambiente, redactando os informes técnicos de medidas preventivas de ataques de lobo na gandería extensiva e non extensiva en Galicia.

Contacto:pedroai@msn.com

\section{Resumo}

Neste ensai o abórdase unha revisión dalgúns dos aspectos da bioloxía e a ecoloxía do lobo no norte de Galicia como un dos elementos que máis inciden na configuración da identidade rural galega e no aproveitamento gandeiro extensivo dos montes e, dentro deste, na cría dos cabalos bravos. Entre realidades cruzadas, como o cultivo intensivo de eucaliptos, os incendios e o cambio climático, o texto tenta atopar unha dirección que seguir nun mundo rural que esmorece.

\section{Abstract}

This essay addresses a review of some aspects of wolf biology and ecology in northern Galicia as one of the elements that most affect the configuration of the Galician rural identity and the extensive livestock use of the mountains and, within it, the breeding of wild horses. Between cross cutting realities, such as intensive eucalyptus cultivation, fires and climate change, the text tries to find a direction to follow in a fading rural world.

\section{Palabras chave}

Lobos e cabalos, trophic cascades, política rural, multinacionais, cambio climático.

\section{Keywords}

Wolves and horses, trophic cascades, rural politics, multinationals, climate change.

\section{Sumario}

\section{Trophic cascades}

2. Dinámica demográfica recente do lobo

3. Lobos e bestas

4. A lei do duplo equilibrio

5. Grupos e supergrupos 
6. Un rural en catatonía

7. Que futuro...

8. Eucaliptos, cambio climático e incendios.

9. Unha nova perspectiva dos lobos e os cabalos

\section{Contents}

1. Trophic cascades

2. Recent demographic dynamics of the wolf

3. Wolves and beasts.

4. The law of double equilibrium

5. Groups and supergroups

6. A rural in catatonia

7. What a future...

8. Eucalyptus, climate change and fires.

9. A new perspective of wolves and horses 


\section{TROPHIC CASCADES}

Unha das conclusións máis interesantes do proceso polo que se reintroduciu o lobo en Yellowstone, ese inmenso parque nacional que hai en Wyoming, do que o lobo levaba ausente máis de seis décadas, foi o de visibilizar en a penas cinco anos a transcendencia que ten na natureza o fenómeno das trophic cascades.

As trophic cascades, ascendentes ou descendentes, virían formarse polas sucesivas influencias que a poboación dunha ou varias especies dun determinado chanzo da pirámide ecolóxica exercen sobre as poboacións das especies pertencentes ao chanzo superior ou inferior, evidenciándose estas influencias, moitas veces, en modificacións intensas das paisaxes e dos hábitats.

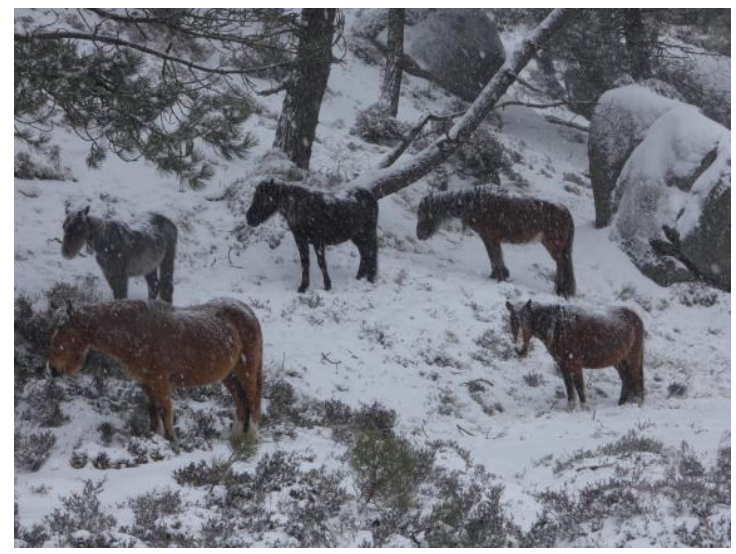

A analoxía máis aparente que se pode encontrar en Galicia destes procesos observados en Yellowstone é a que vincula lobos e bestas con toda unha serie de pequenos e medianos animais, presentes nas grandes chairas e abas dos montes cubertos de toxos e queirugas da Dorsal Galega. Desde pequenos insectos, como a araña tigre (Argiope bruennichi) ou a avelaiña das queirugas, até lebres, coellos, raposos e gatos bravos que fan vida no mato. Que o toxal estea aberto e se poida camiñar por el é cousa das bestas. Mais deixaremos para outra ocasión a descrición deste aspecto da relación de lobos e bestas. Trataremos de trazar unha liña máis alá que una lobos e bestas con vacas e eucaliptos. E para iso faremos un percorrido detallado por unha parte da xeografía galega onde aínda late o pulso dunha natureza singular, mentres esmorece sen remisión un mundo rural onte mesmo fértil e vigoroso: a Serra do Xistral e a súa contorna.

\section{DINÁMICA DEMOGRÁFICA RECENTE DO LOBO}

Se partimos dos dados oficiais do último censo de lobos (2014-2015), no norte da provincia de Lugo e no nordeste da de Coruña había constancia da existencia de 6 grupos reprodutores (DXCN, Xunta de Galicia, 2016). En 2019, un traballo aínda inédito ${ }^{2}$ confimou a reprodución en 18 grupos e unha alta probabilidade noutros 6 casos. Isto significaría un incremento do número de grupos de lobos dun 300 por cento en apenas cinco anos. 0 que se censou en 2014-2015 estaba certamente moi lonxe de ser o que en verdade existía nesa parte do país. Hai información anterior a 2014 que certifica a existencia de non menos de outros 6 grupos reprodutores a maiores dos 6 que aparecen no censo impulsado polaXunta.

Mais o que pode ter maior valor referencial é coñecer a densidade de lobos rexistrada no territorio en cuestión. Falamos duns 3.100 quilómetros cadrados definidos por unha liña que partindo de Ribadeo cara A Pontenova vira cara o oeste, unindo Abadín, Vilalba e Monfero, para ascender cara a península da Capelada, delimitando todas as nacentes dos ríos Xunco, Ouro, Landro, Eume, Sor e Mera. E de aí, ao mar. Un simple cálculo permítenos estimar a densidade de lobos. Atribuíndo a cada grupo un número medio de compoñentes e engadindo unha porcentaxe determinada de dispersantes, obtemos unha aproximación ó número de lobos presente neste territorio. Dividindo este número pola superficie en quilómetros cadrados e multiplicando o resultado por cen temos o valor de densidade, expresado en número de lobos/100 gm2. Neste caso, o valor situaríase entre 10 e 15. Senón o máis alto, un dos máis altos do mundo.

\section{LOBOS EBESTAS}

Os modelos da Optimal Foraging Theory (OFT) sitúan ós poldros sobradamente por riba do punto exacto de equilibrio entre a enerxía que proporcionan e o gasto enerxético de captura que supoñen para un grupo de lobos. Krebs e Davies (1989) formularon o balancear dese equilibrio entre enexía atinxida e gasto realizado para medir e comprender as eleccións das distintas presas dispoñíbeis que podían efectuar os predadores $(\mathrm{E} 1 / \mathrm{H} 1>\mathrm{E} 2 / \mathrm{H} 2$, sendo $\mathrm{E} 1$ a enexía proporcionada pola presa 1 e $\mathrm{H} 1$ o tempo que leva a captura desa mesma presa 1 ). Posteriomente, outros investigadores (Mech \& 
Boltani; 2003, Mech \& Peterson, 2003), repasaron os factores que poden estar involucrados na selección de presa, no tamaño de grupo ou na incidencia da predación sobre a poboación da presa.

Incorporouse ao compendio teórico as inferencias e coñecementos adquiridos na intensa experiencia de Yellowstone (Stahler, Smith \& Guernsey, 2006) e incluso houbo quen contribuíu ao debate achegando información acerca de lobos que depredan sobre grupos migratorios de cervos (Loveless, 2010). Un estudio recente (Barber-Meyer, Mech, Newton \& Borg, 2016), estableceu unha nova hipótese para explicar aparentes contradicións na OFT cos elevados tamaños de grupo observados en casos de lobos que cazan presas perigosas.

O certo é que, tal como observan algúns destes investigadores (Mech \& Boltani, 2003) cando unha relación depredador-presa é ancestral, poden xurdir determinados mecanismos de defensa para amortecer o efecto dos depredadores na poboación das presas. Por exemplo, o mecanismo de "swamping", que é "inundar" ou "encher" de súpeto o territorio onde campa o depredador dun número moi elevado de crías a través da sincronización dos partos. Esta estratexia persegue favorecer a supervivencia dos exemplares novos e, así, incrementar o recrutamento á poboación adulta. Mentres os leóns ou os lobos están ocupados en depredar unhas crías (de ñu ou cebra nas chairas do Serengeti ou de egua no Xistral), outras crías medran rápido e fanse menos vulnerábeis cada día que pasa.

Contamos, ademais, cun dato adicional que certifica a existencia milenaria dos cabalos sobre o chan galaico. Os petróglifos característicos que retratan equinos, montados en escenas de caza ou sen montar, teñen máis de 4000 anos. $\mathrm{E}$, a pesar da entrada de sangue foráneo, a relativa boa conservación dos caracteres raciais no poni galego fai que podamos sentirnos orgullosos de conservar un patrimonio xenético e ecolóxico que entronca directamente cos cabalos retratados nas covas neolíticas da cordilleira Cantábrica.

\section{A LEI DO DUPLO EQUILIBRIO}

Ás veces na natureza podemos encontrar relacións de equilibrio que vinculan pares de variábeis. A concentración de ións de hidróxeno na solución do solo marca a acidez desta, que se mide a través do $\mathrm{pH}$. A acidez da solución do solo determina a posibilidade de pór a disposición ou non os catións existentes no complexo de intercambio catiónico, como por exemplo os catións Mg++ ou Ca++. A maior acidez, menos magnesio dispoñíbel para as plantas e máis ferro. $\mathrm{O}$ pH é o que determina que se "despeguen" ou non os catións de magnesio ou calcio das moléculas de arxila dese complexo de intercambio. As relacións de equilibrio entre acidez e alcalinidade da solución favorecen ou non a adquisición de nutrientes fundamentais para as plantas.

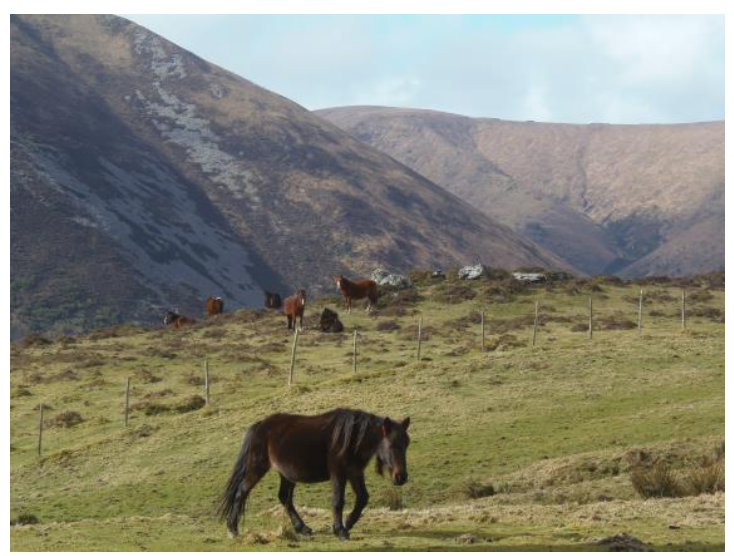

A relación depredador-presa, ou o que nos interesa neste momento, lobo-besta, pode ser descrita a través da estima de varios parámetros, pero o fundamental é a taxa de predación (kill rate), que ven sendo a cantidade de biomasa da presa que un depredador retira do ecosistema por unidade de tempo. Cando un depredador somete a presión depredatoria continua a poboación dunha deteminada presa, esta pode entrar nunha dinámica depresiva e iniciar unha curva descendente que reflicte o baixo recrutamento de crías á súa poboación. Neses casos, o lobo e calquera outra especie de depredador, de dispoñeren dunha outra especie de presa, desprazan a súa preferencia depredatoria cara os individuos máis vulnerábeis da poboación desta. É o que se denomina "switching". No caso dos lobos que depredan sobre as bestas do Xistral, o alimento altemativo pasan a ser os xatos e becerros das vacas que pastan ceibes no monte ou en semi-extensivo. Alí onde as bestas escasean, debido a que os seus propietarios se desfixeron delas ou debido a que a elevada taxa depredatoria impide o recrutamento e favorece o avellentamento da poboación equina, o lobo vai procurar en maior medida o seu alimento nos grupos destas vacas. E, en deteminadas circunstancias, convértese nun 
factor de primeiro orde que condiciona o manexo e o balanzo económico dunha explotación.

\section{GRUPOS ESUPERGRUPOS}

Ás veces, cando o tamaño das presas potenciais é grande e hai risco dos lobos sufriren feridas nos ataques ou cando hai abundancia de alimento, algunhas agrupacións de lobos poden alcanzar un número verdadeiramente elevado. Son coñecidas as cifras de 40, 50 e incluso 60 e máis lobos en concentracións que se forman espontaneamente a partir de grupos non territoriais que migran canda os grandes rabaños de caribús no Yukon (Hayes, 2010). Mais sen ir a terras remotas, hai grupos de lobos que matan cervos uapitís ou alces que poden nomalmente estar formados por entre 15 a 20 lobos. Algo similar pode tamén acontecer en determinados grupos do noroeste ibérico que depredan sobre cabalos, eguas e poldros. Hai constancia de grupos formados por 12-14 lobos no período de outono-inverno. Mais non todos os grupos de lobos que matan equinos salvaxes ou semisalvaxes son tan numerosos. 0 por que uns grupos medran até se converteren en poderosas agrupacións familiares e outros son a penas un trazo das anteriores é, polo de agora, descoñecido.

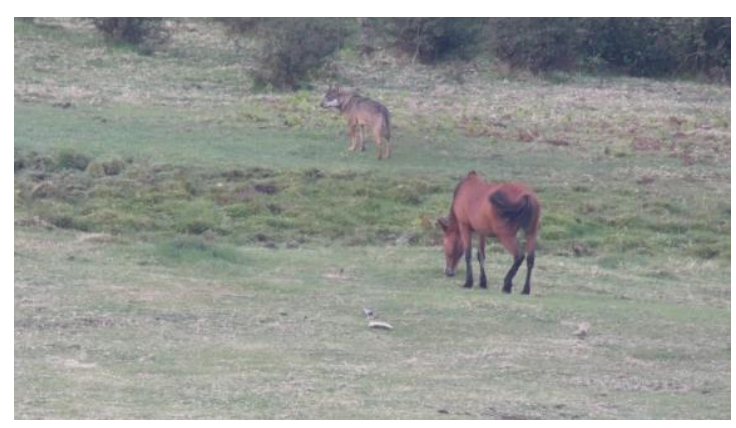

O caso é que cando xorde un destes "supergrupos" a taxa de depredación de poldros se dispara até valores inesperados. Os ataques a poldros de 10-11 meses sucédense nos meses finais do outono e no inverno. Ás veces a penas 2-3 días separan os ataques. Incluso, cando o grupo se fragmenta, pode acontecer que na mesma noite maten en dous sitios distintos, separados varios quilómetros entre si. Entón, a taxa de predación é tan elevada que o número de días entre ataques sucesivos se reduce enormemente durante períodos prolongados, desatando un grave descontento social entre o colectivo propietario das reses. Se estes grupos numerosos non encontran poldros, entón serán os xatos e becerros os que lles proporcionen o alimento. Nesas circunstancias e nesas épocas do ano, hai gandeiros que perden o 10 ou 15 por cento dos xatos.

Unha incidencia que, no contexto adverso actual que atravesa o sector da carne, con conxelación de prezos, diminución de consumo e menor marxe de negocio, pode condicionar a continuidade dunha explotación: a falta de perspectivas de remuda xeracional e a proximidade da idade de retiro estimulan o adianto do abandono da explotación. Cando isto acontece, é normal que a base territorial que soporta a explotación sufra unha transfomación acelerada e que outros aproveitamentos, nomeadamente o forestal, substitúan pradarías e predios a monte.

\section{UN RURAL EN CATATONÍA}

No lugar do Carmen, parroquia de Miñotos, Ourol, hai unha casa na que mora unha familia con dúas nenas, Irene e Xiana. Teñen 12 e 8 anos. No lugar da Torre hai outra nena, Lucía, tamén de 12 anos e en Leborín tamén hai un neno. No Viveiró naceu hai case 3 anos outra crianza. Son como as últimas pebidas de ouro do río Sil en Montefurado. Despois delas, na-da. Nalgunhas zonas do Xistral, máis do 70 por cento da poboación son persoas maiores de 60 anos e en moitos lugares só viven vellos. Cando caia a cortina das súas vidas comezará outra conta atrás.

Os ecos apagados dos rueiros e corredoiras nos que hai anos brincaba a rapazada darán paso ao silencio das hedras. Os eidos coñecerán o ferro das máquinas que desbrozan. Nuns anos, as sombras irán medrando e o sol deixará de quecer nas paredes e patíns, para se impor a nova xeografía da traxedia que se escrebe cada día nas aldeas da montaña galega que mira para o mar Cantábrico. Outro mar, de eucaliptos este, asolagara outro anaco da Galicia. Pasaremos por alí e xa non acertaremos a ver as hedras que nos recordan a agonía. Mais na seguinte curva da estrada, unha procesadora rescatará para a vista unha aldea soterrada vinte anos atrás por ese verdor cincento cobizado por Ence. 
Indalecio, xubilado da mariña mercante, veciño do Albardo, no Valadouro, estende unhas mans como as dos vellos dos retratos de Castelao ao tempo que fai un aceno metade impotencia e metade comprensión. Ven do pasteiro onde acaba de encontrar os restos de dous xatos. 0 lobo matounos a media mañá protexido polo barruzo e a néboa. Ten 190 vacas. Cada ano, o lobo mátalle entre 40 e 50 xatos e becerros. El é un caso aparte. Non lle ten odio. Vai deixar escrito no testamento que 25 vacas serán para o lobo.

Cando non lle matan os xatos a Indalecio, os lobos visitan os poldros de Javier Fraga ou de Ramón Seijas, nos pastos de Madriñán ou Sinás, onde os antigos deron sepultura hai 4000 anos a un xefe local. Javier ten 60 bestas. Cada ano nacen sobre 45-50 poldros. Ao rematar o ano, a Javier non lle restan máis que 4 ou 5 poldros. Así desde hai máis de 5 anos. Teimudo, hai 15 anos deulle por recuperar xunto con outros veciños a rapa das bestas de Miñotos, que se celebra nun curro no monte de Madriñán. Afima que desde hai 10 anos a poboación de bestas caeu máis dun 50 por cento, entre as greas que se venderon polo abandono dos propietarios, $\mathrm{xa}$ vellos, a falta de recrutamento polo elevado número de poldros que matan os lobos e, finalmente, porque as eguas van morrendo de vellas. No Pereiro, no Cadramón e na Balsa, a tendencia é a mesma.

As bestas e as vacas de Manolo das Folgueiras, José da Caxigueira, Carlos de Leonte, Elvira de Caraceiro ou Olga da Carballeira padecen con maior ou menor frecuencia os ataques dos lobos. Non todos os ataques son cubertos economicamente polas indemnizacións da Xunta. Cando non se encontran os restos, algo frecuente en poldros e xatos de poucos días, o propietario non recebe máis resposta que unha negativa. Quen sabe diso xa nin se molesta en denunciar unha nova perda nesas circunstancias. Poldros ou xatos de dúas ou tres semanas apenas pesan 15-30 quilos. Mata-los, come-los ou leva-los para seguir comendo neles en lugar seguro é doado para un grupo de lobos. Encontrar os restos nestes casos é ben complicado. Algúns que se din expertos reclaman que hai que baixar as bestas antes dos partos, ou ao pouco tempo de pariren, para predios próximos ao lugar. Mais cando a besta é retirada do monte e se lle priva de roer no mato, a eficiencia da súa nutrición a base da herba dos prados non é como a da vaca. Axiña hai que mercar rolos de herba para darlles de comer. 0 gasto dispárase. E, ademais, quen concibe baixar 150 ou 200 bestas desde o monte veciñal para innumerábeis predios pechados, mantelas a herba e, chegado setembro ou outubro, botalas outra vez para o monte a pasar o inverno? É precisamente nos meses de primavera e verán cando estes animais se nutren de vizosos pastos de altura, bebendo nas fontes de auga fría da serra como hai miles de anos, para poder despois enfrontar as galernas e invernías.

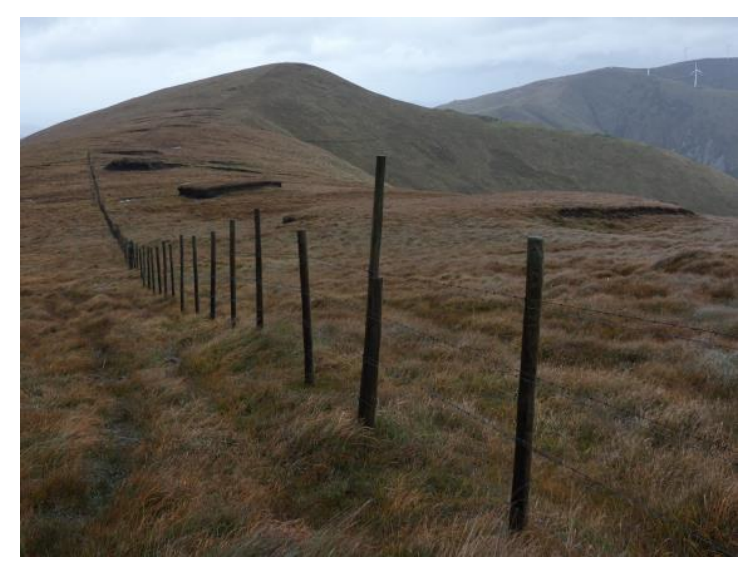

\section{QUE FUTURO...}

Pancha é unha poldriña de 3 semanas. Nacida no virulento mes de abril nos pastos da Pena dos Camiños, é filla dunha egua que non a quería. Na mesma grea, unha egua ruana de máis de 25 anos e cega acaba de ter o seu último poldro. Con 6 días de vida, o poldriño segue a nai entre penedos a través de carreiros nos matos, a penas se separa dela. A Pancha, en cambio, houbo que baixala. Agora ocúpanse dela Xiana e Irene, que lle dan leite por biberón, aínda que xa vai roendo na herba.

A xente que ten bestas e que sabe que van a menos non se cansa de repetilo: "Así que van a menos as bestas, os lobos van polos xatos. Entón que? Que nos queda? Marchar para un piso en Viveiro?". Desa opinión é Javier, que se resiste a abandonar a súa casa nas Cernadas, Miñotos. Ben sabe que o abandono trae consigo o medre do eucalipto. Boa parte da zona baixa da vertente norte da Serra do Xistral está xa cuberta por masas de eucalipto que ocultan nas súas tripas máis de 60 aldeas abandonadas. Delfina, que era a nai de Javier e que faleceu o pasado mes de febreiro, nacera en 1928 e lembraba con todo detalle a vida daquelas aldeas, algunhas cheas de nenos e nenas que corrían polos eidos e brincaban nas leiras, rapazada que barullaba nas corredoiras de camiño ás festas. Unha vitalidade que se medía nas transaccións 
de gando, acordadas no mesmo monte ou en feiras como a de Gontán. Eran os anos previos á catarse que viviu o agro galego nos anos $60 \mathrm{e}$ 70 , momento no que se podería situar o inicio da hecatombe.

Hoxe, a inercia é inexorábel. 0 abandono non cesa. Viveiro, Burela e Cervo foron os destinos da maioría da xente que marchou das aldeas. Instaladas en pisos, centos de familias renunciaron á vida no campo e abrazaron os salarios do aluminio e a comodidade das vilas. Venderon as vacas e encheron de eucaliptos as leiras. 0 proceso segue hoxe. Ence gaña a batalla por goleada.

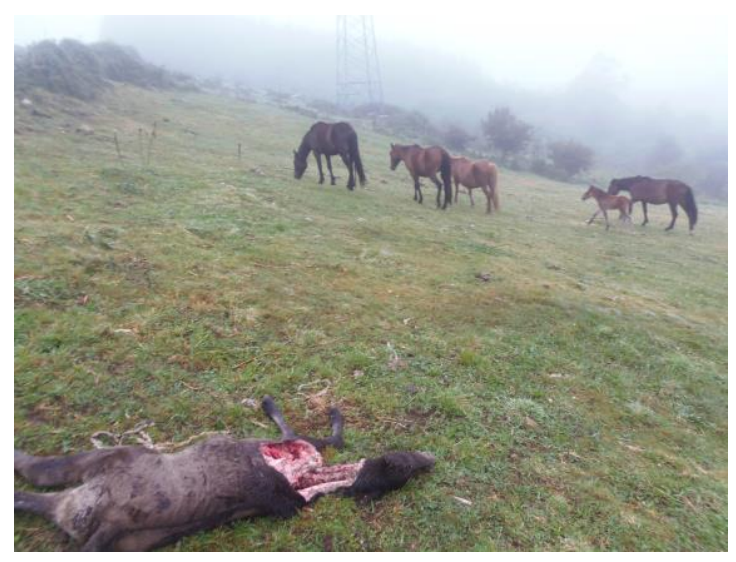

\section{EUCALIPTOS, CAMBIO CLIMÁTICOE INCENDIOS}

Nos últimos anos vimos como se vai transformando en Galicia o modelo tipo de incendio cara un fogo a grande escala que se propaga a saltos, con labaradas que parecen cabalgar sobre os montes, cuspindo brasas que rapidamente prenden novos focos ao pousar sobre herba seca. En inglés chaman a estes focos secundarios "spot fires" e "spotting ignition" ó xeito en que se foman, porque o foco principal, nomalmente de dimensións descomunais e con grande poder convectivo, proxecta miles de brasas á contorna e a alturas inverosímiles, impulsadas por correntes ascendentes capaces de suspender mesmo fragmentos de troncos de árbores.

Esta transformación, segundo os expertos, tería a ver co cambio climático que experimenta o planeta. É máis, son coñecidas as predicións sobre as mudanzas climáticas e os seus efectos na aparición deste tipo de lumes na Galicia, porque a conxunción de factores que favorecen esa aparición está a ser e será máis frecuente: primeiro, un medio de ignición e propagación do lume moi seco pola acción de secuencias máis intensas e prolongadas de ventos do nordés e, segundo, a entrada regular de masas de ar e ventos cálidos, sen aportación de precipitación, cara fin dos veráns. Un escenario capaz de convocar episodios dantescos de destrución e morte.

Neste sentido, convén citar tan só un estudo da revista Hidrogeology Journal (Raposo, Dafonte \& Molinero, 2013). Este estudo pretendía avaliar, por medio dun modelo específico, os impactos potenciais das alteracións climáticas na recarga de auga subterránea na bacía hidrolóxica Galicia-Costa. Pois ben, o traballo concluíu que os efectos na recarga media anual da auga subterránea son pequenos, máis que as alteracións climáticas que si influencian fortemente a súa variabilidade temporal, de maneira que esta pode concentrarse na estación invernal e decrecer dramaticamente nas estacións de veránoutono. Os autores estimaron que a duración da estación seca podería verse incrementada cerca dun 30 por cento (é dicir, un mes a maiores). Algo concomitante co que se pensa que está a acontecer en "superficie", coa prolongación e agudización de períodos secos extremos e a posterior sucesión de precipitacións intensas e tormentosas en períodos concentrados de outono e inverno.

Este fenómeno, que probablemente se manifeste con maior intensidade nas Rías Baixas, será común a todo o cuadrante noroccidental ibérico. Del tampouco escapará A Mariña. Só que na Mariña, o risco de que aparezan situacións extremas de destrución será maior. Porque as distancias entre as masas de plantíos de especies pirófilas como o eucalipto e as aldeas son mínimas.

0 abandono de terras agrarias, maiomente prados, e a propagación dos plantíos de eucalipto, dan lugar a un proceso de transformación de enome envergadura, no que non se respectan distancias de seguridade nin ao redor de núcleos de poboación nin ao longo das vías de comunicación. Isto da unha idea da incidencia que podería ter un deses grandes lumes nas propiedades. Mais existe un outro factor enormemente preocupante: as distancias tamén son cada vez menores a ese enome banco combustible que se aloxa nos solos do Xistral, a turba. Aínda hoxe é lembrado un incendio especialmente voraz que aconteceu nos anos 80 , no que a turba da serra botou semanas a arder.

Por outro lado, no plano económico, o impulso dunha especialización produtiva tan extrema, centrada exclusivamente na produción silvícola de madeira de especies de crecemento rápido 
que se vende a un só comprador, só pode conducir á depreciación do produto e á percepción de rendas cativas impostas sempre en réxime monopolista.

Igualmente, hai que salientar que a incidencia ambiental destes aproveitamentos silvícolas é extrema. Entre outros factores negativos, pódense citar descensos significativos na biodiversidade, incremento de procesos erosivos tras as cortas, afeccións intensas dos cursos de auga debido ós arrastres procedentes das ladeiras cortadas e baixa reversibilidade das plantacións, pola dificultade de erradicación das árbores e os seus tocóns e polo deterioro da fertilidade e capacidade produtiva dos solos tras dúas ou tres quendas de corta.

Con estas premisas, non parece moi afortunado un modelo de desenvolvemento territorial de tan baixo beneficio social, elevado impacto ambiental e enorme risco de padecer episodios catastróficos de magnitude difícil de calibrar. É máis, todo indica que este proceso de transformación debería ser obxecto dunha intervención urxente das institucións públicas, sostida no tempo e de necesaria profundidade, para tentar reconducir os factores que o impulsan.

\section{UNHA NOVA PERSPECTIVA DOS LOBOS E OS CABALOS}

Ben avanzado o século XXI, e máis alá do debate acerca do seu carácter salvaxe ou doméstico, aínda está pendente o recoñecemento da relevancia ecolóxica dos cabalos que pastan libres nos nosos montes, co conseguinte despregamento dunha estratexia que protexa, fomente e reforce a presenza dos equinos galegos, apoiando economicamente os propietarios para favorecer o seu mantemento, conservación e selección racial. Se na Irlanda de 1926 máis de 5000 persoas asistiron ao enterro e funeral de Cannon Ball, o ilustre semental de Conamara Pony que tanto contribuíu á recuperación desta raza de poni (Lyons, 2010), na Galicia de case cen anos despois esvara sobre as nosas conciencias o progresivo deterioro xenético e mesmo a desaparición física dos garranos nos montes do país.

En serras como as do Suído, Faro de Avión, Castrove, Xiabre ou Testeiro, e nos montes da Costa da Morte e amplas áreas da Serra do Xistral e contorna, o número de bestas non para de baixar. Matadoiros como o de Betanzos déronlle pasamento a milleiros de cabalos nos peores anos da crise iniciada en 2007. E o declive demográfico do noso rural, sobre o que cabalgan a incidencia do lobo e o desenfoque da PAC en relación aos cabalos, ameaza con barrer a medio prazo a persistencia da tradición ancestral da cría das bestas nos montes. Que facer ante este perigo, sendo conscientes de que a existencia dos cabalos vai ligada á das aldeas?

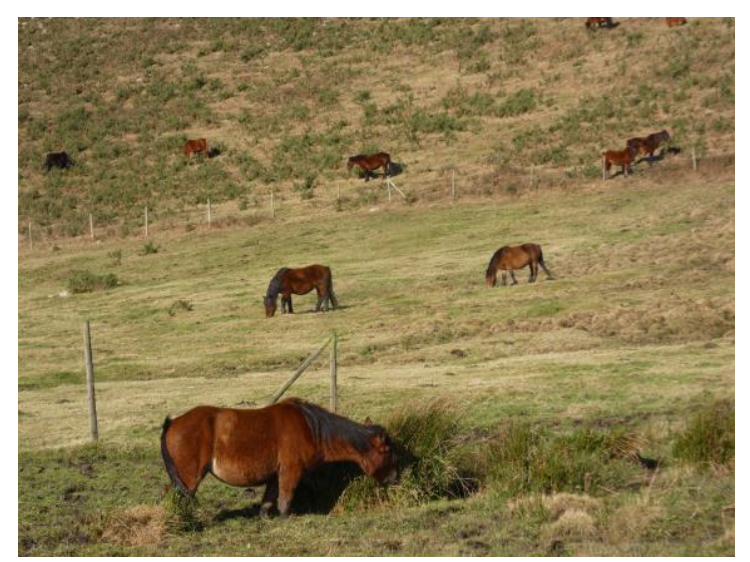

A pesar das analoxías, Galicia non é Yellowstone. En zonas como o Xistral, balancear o equilibrio ancestral dun territorio de sempre manexado implica asumir a necesidade de regular e limitar a poboación de lobos. Matar lobos pode ser necesario, aínda que produza unha enome dor. Mais non é suficiente. Deseñar todo un conxunto de medidas transversais destinadas a construír o último dique de contención da extinción do rural é algo máis que unha urxencia. E o Xistral pode ben ser un campo onde experimentar plans innovadores que contribúan ao mantemento das rendas agrarias, á diversificación das producións e do emprego e, en definitiva, a fixar poboación.

Trátase de evitar a perda definitiva de porcións enteiras de Galicia para entregarllas a unha multinacional sempre disposta a seguir devorando cachos do país. Porque iso non só tería un custe ecolóxico que implicaría a desaparición de cabalos, vacas, xente e lobos. Engadiríamos outro pesado elo a esa cadea que nos somerxe nese inmenso océano da historia onde tantos pobos afogaron e desapareceron para sempre. Estamos a tempo de evita-lo? 


\section{NOTAS}

10 texto é unha versión do autor da primeira escrita publicada na revista galega en iiña Tempos dixital o pasado 19 de decembro:https://temposdixital.gal/

2 P. Alonso e D. Martínez realizaron este informe.

\section{REFERENCIAS BIBLIOGRÁFICAS}

- Barber-Meyer, S.M., Mech, L.D., Newton, W.E. \& Borg, B.L. (2016). Differential wolf-pack-size persistence and the role of risk when hunting dangerous prey. Behaviour, 153(12), 1473-1487. DOI: https://doi.org/10.1163/1568539X00003391.

- Dirección Xeral de Conservación da Natureza, Consellería de Medio Ambiente (2016). Censo de lobo ibérico en Galicia. 2013-2014-2015.

- Hayes, B. (2010): Wolves of the Yukon. Firefly Books LTD.

- Krebs, J. R. \& N.B. Davies (1989). An Introduction to Behavioral Ecology. [4 ${ }^{\mathrm{a}}$ ed.]. Blackwell Scientific Publications.

- Loveless, K. (2010). Foraging strategies of eastern wolves in relation to migratory prey and hybridization. [Masters thesis, Trent University].

- Lyons, L. (2010, july 6). Connemara ponies and Cannon Ball. Oughterard Heritage.

https://www.oughterardheritage.org/content/topi cs/connemara-ponies-and-cannon-ball.

- Mech, L.D. \& Boitani, L. (2003). Wolf social ecology. In Mech, L.D. e Boitani, L. (eds.). Wolves. Behavior, ecology and conservation. The University of Chicago Press.

- Mech, L.D. \& Peterson, R.O. (2003). Wolf-prey relations. In Mech, L.D. e Boitani, L. (eds.). Wolves. Behavior, ecology and conservation The University of Chicago Press.

- Raposo, J. Dafonte, J. \& Molinero, J. (2013). Assessing the impact of future climate change on ground water recharge in Galicia-Costa, Spain. Hidrogeology Journal, (21), 459-479. DOI: https://doi.org/10.1007/s10040-012-0922-7.

- Stahler, D., Smith, D.W. \& Guernsey, D. (2006). Foraging and feeding ecology of the gray wolf (Canis lupus): Lessons from Yellowstone National Park, Wyoming, USA. The Journal of Nutrition 136(7), 1923S-1926S. DOI:

https://doi.org/10.1093/jn/136.7.1923S. 